\title{
Immunohistochemical studies on synapse formation by embryonic cerebellar tissue transplanted into the cerebellum of the weaver mutant mouse
}

\author{
Hideichi Takayama ${ }^{2}$, Shinichi Kohsaka ${ }^{1}$, Tomofumi Shinozaki ${ }^{2}$, \\ Hiroshi Inoue ${ }^{2}$, Shigeo Toya ${ }^{2}$, Tetsufumi Ueda ${ }^{3}$ and Yasuzo Tsukada ${ }^{1}$ \\ 'Department of Physiology, and '2Department of Neurosurgery, School of Medicine, Keio University, Tokyo \\ (Japan) and ${ }^{3}$ Department of Pharmacology and Psychiatry, Mental Health Research Institute, The \\ University of Michigan, Ann Arbor, MI 48109 (U.S.A.)
}

(Received 17 April 1987; Revised version received 24 April 1987; Accepted 27 April 1987)

Key words: Synapsin I; Weaver mutant mouse; Transplantation; Cerebellum; Granule cell; Synapse

Normal cerebellar tissue, obtained from 15-day-old CBA/JNCij mouse embryos, was transplanted into the cerebellum of 4-week-old weaver mice. At the 6th week after the transplantation, the grafted tissue was distinguishable from the host cerebellum, developing a trilaminar organization. The formation of synapses by the implanted granule cells was analyzed immunohistochemically with antiserum against synaptic vesicle protein, Synapsin I. Some areas in the host cerebellum as well as in the grafted tissue were intensely stained by anti-Synapsin I serum, suggesting that the implanted granule cells make synaptic contacts with the neuronal cells.

Transplantation of neural tissue has been used extensively as a viable approach to studying the development of the neural cells in the central nervous system [4-7]. To investigate the behavior of the transplanted neuronal cells in the host brain, it is of advantage to use a mutant mouse which is deficient in a single class of neuronal cells. The weaver mutant mouse is characterized by degeneration of cerebellar granule cells in early postnatal development [8-10]. Electron microscopic studies demonstrated that the synaptic contacts between the Purkinje cell dendrites and the granule cells are extremely poor in the cerebellum of this mutant [11]. Dolphin and Greengard [3] also reported that the amount of Synapsin I, which is a phosphoprotein specific to the membranes of synaptic vesicle $[1,2,13]$, is markedly reduced. It is of interest to investigate whether the implanted granule cells can survive and develop synaptic contact in the weaver mouse cerebellum. In the present study, we transplanted embryonic cerebellar tissue taken from 15-day-old normal mouse embryos (CBA/JNCij) into the cerebellar vermis of 6-week-old weaver mutant mice. Immuno-

Correspondence: S. Kohsaka, Department of Physiology, School of Medicine, Keio University, 35 Shinanomachi, Shinjuku-ku, Tokyo 160, Japan. 
histochemical examinations were conducted with special reference to the synaptic remodeling, by using antiserum to Synapsin $\mathrm{I}$.

B6CBA/F1 $(w v /+)$ mice were purchased from the Jackson Laboratory (Bar Harbor, ME, U.S.A.). The homozygous weaver mutant mice were obtained by mating known heterozygotes for the weaver mutation and were identified by their abnormal gait, and by their smaller size compared with their littermates. Timed pregnant CBA/ JNCij mice were purchased from Nippon Bio-supply Center (Tokyo, Japan).

The cerebellar primordia were dissected from 15-day-old CBA/JNCij mouse embryos (E15). Four-week-old weaver mice were anesthetized with ether and ketamine hydrochloride and held in a stereotaxic apparatus with ear bars. Under aseptic conditions, a small craniotomy was performed in the middle of the occipital bone to expose the surface of the cerebellar vermis and a syringe containing small pieces of embryonic cerebellar tissue was lowered to a depth of $1.0 \mathrm{~mm}$ from the cerebellar surface. The grafted tissue was injected to the host cerebellum by depressing the plunger.

The mice were sacrificed 6 weeks after the transplantation, then anesthetized with ether, and perfused through the left cardiac ventricle with $10 \%$ formaldehyde in phosphate-buffered saline (PBS). The fixed brains were then dehydrated, embedded in paraffin and cut sagittally into $4 \mu \mathrm{m}$ thick sections. Ungrafted cerebella from 10week-old weaver mutant and normal CBA/JNCij mice were also prepared for immunostaining in the same manner. The deparaffinated sections were immunohistochemically stained with anti-Synapsin I serum by the PAP method [12] as reported previously [1].

As shown in Fig. $1 \mathrm{~b}$, the cerebellar vermis of the ungrafted weaver mutant mouse was almost devoid of granule cells and failed to develop the trilaminar structure. The molecular layer was greatly reduced in thickness, and the arrangement of Purkinje cells was quite irregular. The cerebella of weaver mutant and normal CBA/JNCij mice were immunohistochemically stained with anti-Synapsin I serum. As shown in Fig. 1c, the molecular layer and the glomeruli in the granule cell layer were positively stained in the normal control mouse. The positive staining in the molecular layer may indicate the existence of numerous synapses between the parallel fibers and the Purkinje cell dendrites. In the weaver mutant mouse, Synapsin I immunoreactivity in the molecular layer was greatly reduced, and only sparsely distributed dots of immunoreactivity were detected in the whole cerebellum (Fig. 1d). These results agree with the previous observation that the amount of Synapsin I in the weaver mutant cerebellum is reduced by $65 \%$ compared with the normal mouse. Consequently, if intense immunoreactivity with Synapsin I is observed in the weaver mutant mouse with grafted tissue, it is likely that a synaptic contact will be developed by the implanted neuronal cells.

The development of the grafted tissue was examined at the 6th week after the transplantation by hematoxylin/eosin staining. A large mass of grafted tissue was detected in the host cerebellum of the recipient weaver mutant mouse (Fig. 2a). It appeared to be anatomically integrated with the host brain, and had developed a trilaminar organization (Fig. 2b). Many granule-like cells and Purkinje cells were visible, forming the granule cell, Purkinje cell and molecular layers. Most interest- 

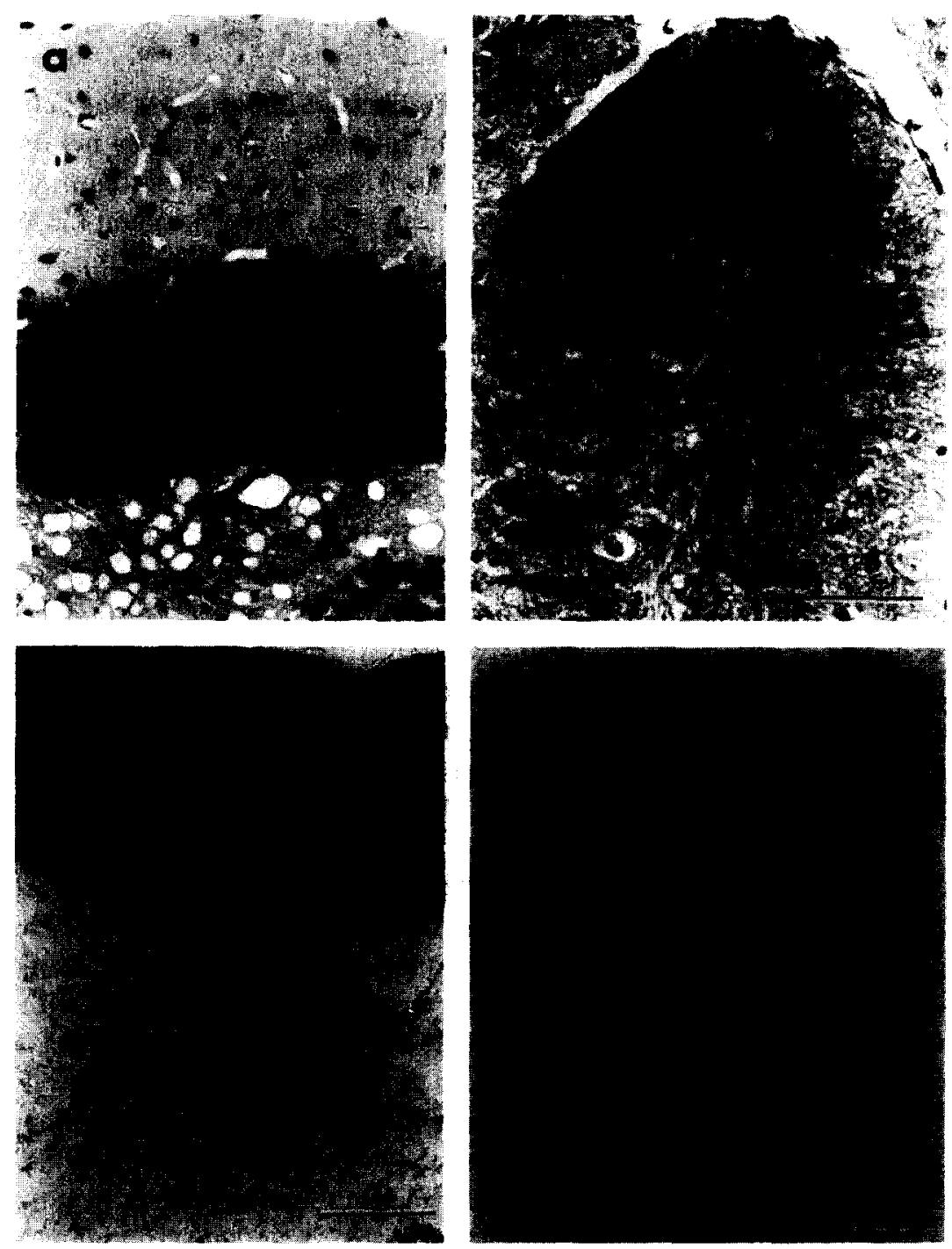

Fig. 1. Sections from the cerebella of 10-week-old control (a) and weaver (b) mice, stained with hematoxylin/eosin. The adjacent sections were immunohistochemically stained with antiserum to Synapsin I. c, control; d, weaver. $\mathrm{Bar}=50 \mu \mathrm{m}$.

ingly, a number of granule-like cells were detected in the folia of the host cerebellum (Fig. 2c). This finding indicates that the implanted granule cells may have migrated from the grafted tissue into the host cerebellum.

These sections were immunohistochemically stained with anti-Synapsin I serum. Fig. $2 \mathrm{~d}$ shows the immunoreactivity in the grafted tissues indicated in Fig. $2 \mathrm{~b}$. The area surrounded by the granule-like cell layer was positively stained by the antiserum, which indicates that synapse formation between implanted granule-like cells and Purkinje cells may have developed in the grafted tissue. Moreover, some areas in the host 

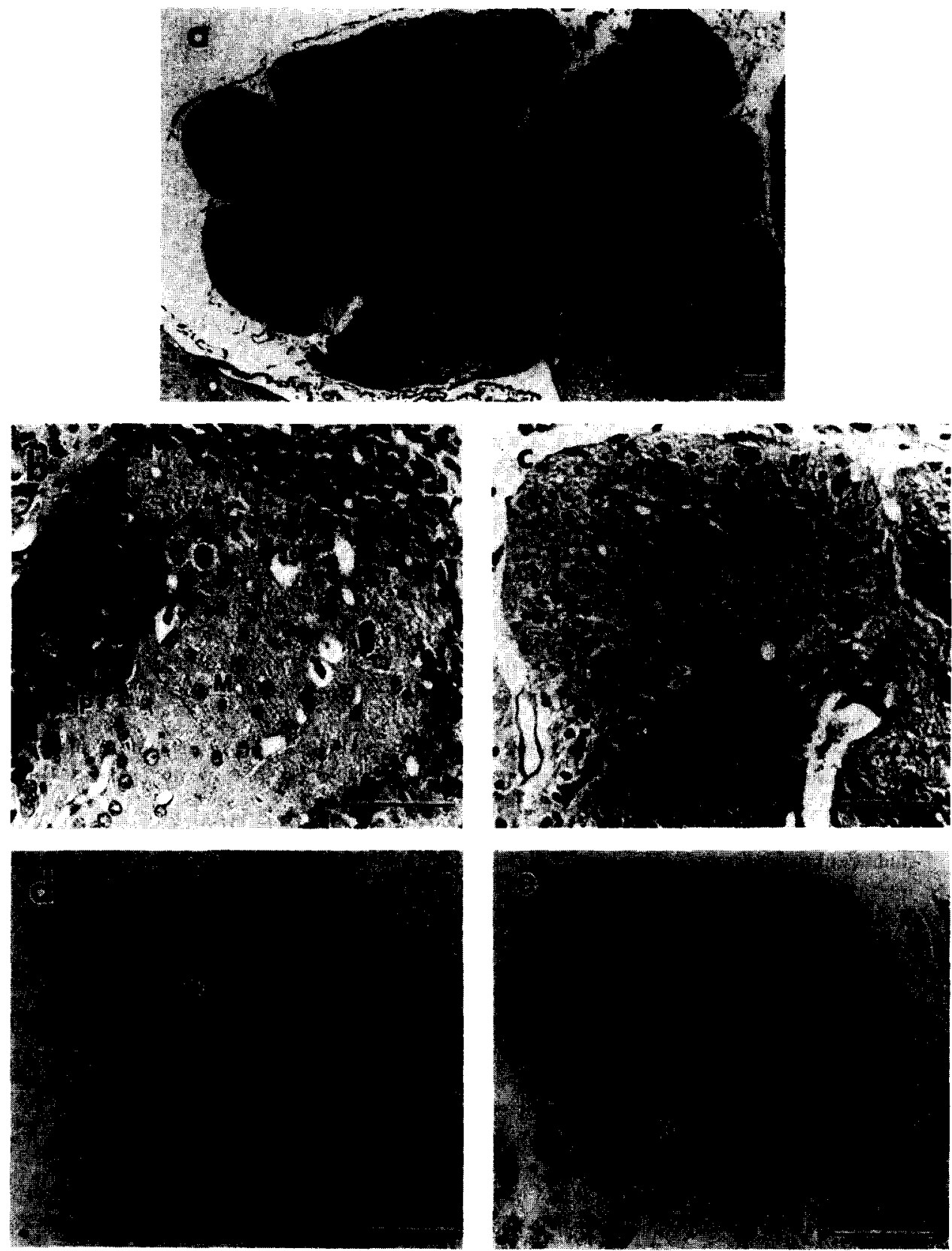

Fig. 2. Sections from the cerebellum of a weaver mouse, stained with hematoxylin/eosin (a-c) and with anti-Synapsin I serum (d,e) 6 weeks after the transplantation. (a) A large mass of grafted tissue was observed as indicated by arrowheads. (b) High magnification of the grafted tissue. Granule-like cells (G), Purkinje cells (P) and the molecular (M) layers were developed. (c) High magnification of the host cerebellum where the implanted granule-like cells were detected as indicated by arrows. (d) Synapsin I staining of the section adjacent to that in (b). Asterisks in (b) and (d) indicate the corresponding areas between two sections. (e) Synapsin I staining of the section adjacent to that in (c). Asterisks in (c) and (e) indicate the corresponding areas between two sections. Bar $=50 \mu \mathrm{m}$. 
cerebellum, where the implanted granule-like cells had migrated, as indicated in Fig. 2c, were also positively stained with anti-Synapsin I serum (Fig. 2e). This result raises the possibility that implanted granule cells extend fibers and make synaptic contacts with the host neuronal cells.

From these results, it is suggested that implanted granule cells integrate themselves with the host cerebellum as well as with the grafted tissue and make synaptic contacts with the neuronal cells. This possibility is currently under investigation by electron microscopic studies.

This work was partially supported by a Grant-in-Aid from the Ministry of Education, Science and Culture.

1 Bloom, F.E., Ueda, T., Battenberg, E. and Greengard, P., Immunocytochemical localization, in synapses, of protein I, an endogenous substrate for protein kinases in mammalian brain, Proc. Natl. Acad. Sci. USA, 76 (1979) 5982-5986.

2 De Camilli, P., Harris, S.M., Huttner, W.B., and Greengard, P., Synapsin I (protein I), a nerve terminal-specific phosphoprotein. II. Its specific association with synaptic vesicles demonstrated by immunocytochemistry in agarose-embedded synaptosomes. J. Cell Biol., 96 (1983) 1355-1373.

3 Dolphin, A.C. and Greengard, P., Presence of protein I, a phosphoprotein associated with synaptic vesicles, in cerebellar granule cells, J. Neurochem., 36 (1981) 1627-1631.

4 Inoue, H., Kohsaka, S., Otani, M., Toya, S. and Tsukada, Y., The effect of arcuate nucleus transplantation on the development of the anterior pituitary in monosodium glutamate-treated rats, Neurosci. Res., 3 (1986) 555-567.

5 Inoue, H., Kohsaka, S., Yoshida, K., Otani, M., Toya, S. and Tsukada, Y., Cyclosporin A enhances the survivability of mouse cerebral cortex grafted into the third ventricle of rat brain, Neurosci. Lett., 54 (1985) 85-90.

6 Inoue, H., Kohsaka, S., Yoshida, K., Otani, M., Toya, S. and Tsukada, Y., Immunohistochemical studies on mouse cerebral cortex grafted into the third ventricle of rats treated with cyclosporin A, Neurosci. Lett., 57 (1985) 289-294.

7 Kohsaka, S., Yoshida, K., Inoue, Y., Shinozaki, T., Takayama, H., Inoue, H., Mikoshiba, K., Takamatsu, K., Otani, M., Toya, S. and Tsukada, Y., Transplantation of bulk-separated oligodendrocytes into the brains of shiverer mutant mice: immunohistochemical and electron microscopic studies on the myelination, Brain Res., 372 (1986) 137-142.

8 Rakic, P. and Sidman, R.L., Sequence of developmental abnormalities leading to granule cell deficit in cerebellar cortex of weaver mutant mice, J. Comp. Neurol, 152 (1973) 103 132.

9 Rakic, P. and Sidman, R.L., Organization of cerebellar cortex secondary to deficit of granule cells in weaver mutant mice, J. Comp. Neurol., 152 (1973) 133-162.

10 Rezai, Z. and Yoon, C.H., Abnormal rate of granule cell migration in the cerebellum of 'weaver' mutant mice, Dev. Biol., 29 (1972) 17-26.

11 Sotelo, C., Anatomical, Physiological and biochemical studies of the cerebellum from mutant mice. 2. Morphological study of cerebellar cortical neurons and circuits in the weaver mouse, Brain Res., 94 (1975) 1944.

12 Sternberger, L.A., Hardy, P.H., Cuculis, J.J. and Meyer, H.G., The unlabeled antibody-enzyme method of immunohistochemistry. Preparation and properties of soluble antigen-antibody complexes (horseradish-antihorseradish peroxidase) and its use in identification of spirochetes, J. Histochem. Cytochem., 18 (1970) 315-333.

13 Ueda, T., Maeno, H. and Greengard, P., Regulation of endogenous phosphorylation of specific proteins in synaptic membrane fractions from rat brain by adenosine $3^{\prime}: 5^{\prime}$-monophosphate, J. Biol. Chem., 248 (1973) 8295-8305. 